\title{
Cosmetic-Regulations, Research \& Marketing challenges and global compliance: An overview
}

\author{
Mohd Riyaz Beg
}

The prime motive of any regulatory compliance is to provide quality product which is safe and effective to the human use. With the same notion of quality, safety and efficacy along with some prime regulatory requirements like nomenclature \& labeling comprises the cosmetic legislations in order to regulate the cosmetic products in the market. The safety assessments of cosmetic products are affected by the differences outlined by the regulatory authorities across globe.

\section{Introduction}

Cosmetics are not only important to influence the global GDP about also give a freedom to enhance the social lives of humans across the nations. The use of cosmetics is not new rather the roots has already been transplanted as early as Egyptian, Greek, and Roman eras. Some unique examples from the books of history suggested that Neanderthal man painted his face with reds, browns, and yellows derived from clay, mud, and arsenic. Bones were used to curl hair. Makeup, tattoos, and adornments conveyed necessary social information. Galen, an ancient Greek physician, invented cold cream. The Romans used oil-based perfumes on their bodies, in their baths and fountains, and applied them to their weapons. Crusaders of the 13th century brought fragrances back to Europe from the Far East. The perfumes developed during the 16th century were powders or gelatinous pastes. Natural perfumes were made from a variety of ingredients containing aroma. Here, with this article we will try to cover the different aspects related to cosmetic regulations in different countries and unions sideways we will also try to compare the market scenario and latest innovations in the world of cosmetics.

\section{Market Outlook}

According to the latest market research from Lucintel, the global beauty market to expected to reach $\$ 265$ billion in 2020 due to an increase in GDP. Asia cosmetic chemicals market to represent the fastest expanding region with 7.6\% CAGR forecast during 2013 to 2018. Saudi Arabia, closely followed by Iran and the UAE, are the top 3 countries in terms of cosmetics consumption in the middle east. China has been catching up with the US in terms of cosmetics consumption. Annual sales growth in China of beauty and personal care products is averaging $15 \%$ and is expected to reach US $\$ 38$ billion this year. Unlike the rest of the world, where skin care products represent less than $30 \%$ of the market, in China, skin care represents $40 \%$ of the cosmetics and toiletries market. The tripling in the size of Africa's middle class over the last 30 years to what the African Development Bank estimates is now 313 million people, coupled with increased urbanisation, are driving the growth of the continent's cosmetics industry and markets. Euromonitor International predicts that by 2016 Nigeria's young yet increasingly sophisticated population will drive industry sales to $\$ 620.2 \mathrm{~m}$. Valued at $\$ 42$ billion in 2012 Represents $58 \%$ of the Latin American beauty and personal care market Home to over 2,000 cosmetic, toiletry and fragrance manufacturers Now the 3rd biggest cosmetics and toiletries 
market in the world. The United States currently represents the single largest market worldwide. Annual sales of approximately US\$55 billion.

The most preferred cosmetics lines are the colour and makeup segment with values slightly more than $18 \%$ of the total personal care market. As far as concerned to the cosmetics market in India which is mounting about 20 percent annually, twice as fast as that of the US and European markets.

When we talk about the cosmetic ingredients market then according to BCC Research, the total global cosmetic and toiletry ingredients market value is expected to reach $\$ 24.5$ billion in 2018 after increasing at a five-year (CAGR) of 4.6\%. Apart from that Organic personal care products market is growing at rapid pace across the world. According to analysts Transparency Market Research, global demand for organic personal care products is expected to reach $\$ 13.2(€ 10.1)$ billion by 2018 , growing at a CAGR of 9.6 per cent. The US demand for organic products is estimated to grow by over 10\% from 2012 to 2018. Strong awareness about the efficacy of organic personal care products and lifestyle changes are key drivers in this region.

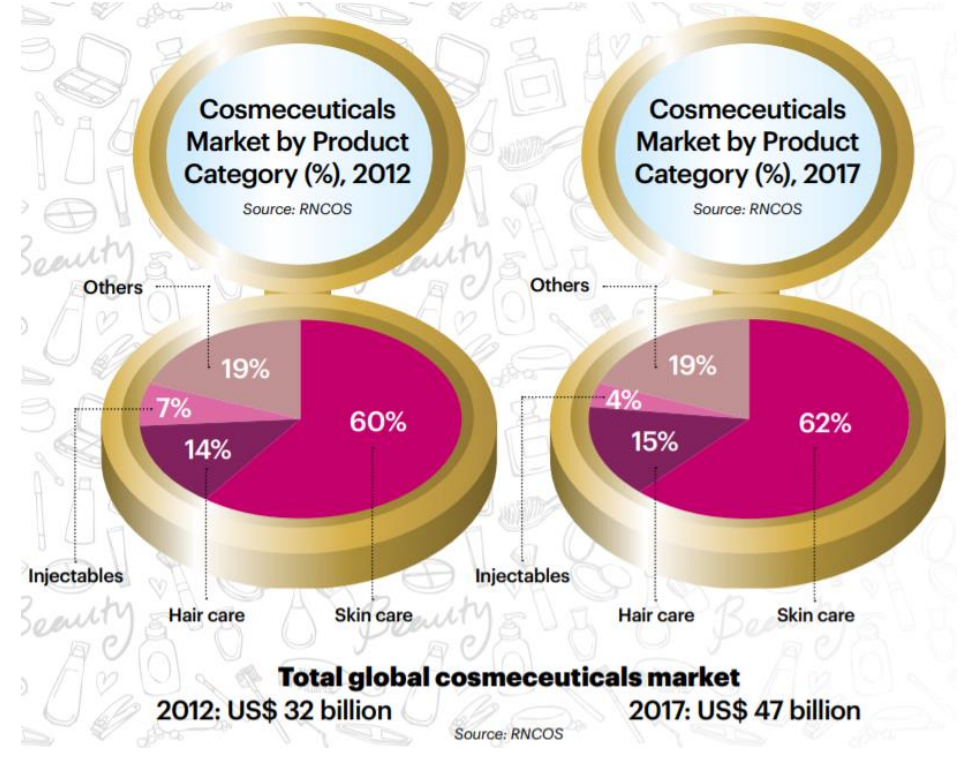

\section{Top Cosmetic companies which are driving block for the whole industry} As per the global market share in sales, L'Oreal SA remains the global leader in cosmetics with a $16.8 \%$ market share and 2000 gross sales of roughly $\$ 4$ billion, according to Euromonitor International. Estee Lauder Company (10.9\%), Procter \& Gamble Company (9.3\%), Revlon Inc. (7.1\%), and Avon Products Inc. (4.7\%) round out the top five. Shiseido Company Limited (4.2\%), Coty Inc. (3.3\%), Kanebo Limited (2.1\%), Kose Company Limited (2\%) and Chanel S.A. (1.7\%) round out the top 10 . Together these producers account for $62.1 \%$, or $\$ 15.15$ billion, of the total $\$ 24.4$ billion global cosmetics market. The balance of the top 20 global cosmetics companies - LVMH, The Body Shop PLC, Mary Kay Inc., Kao Corp., Yves Rocher SA, Pola Cosmetics Inc., Beiersdorf AG, Oriflame International SA, Alticor Inc., and the Boots Company PLC - account for a roughly combined $11 \%$ of market share, according to Euromonitor International. Overall, the top 20 cosmetics producers accounted for roughly $73 \%$ of the global marketplace. 
Mohd Riyaz Beg, M. Pharm (Pharmacology), Institute of Chemical Technology, Mumbai

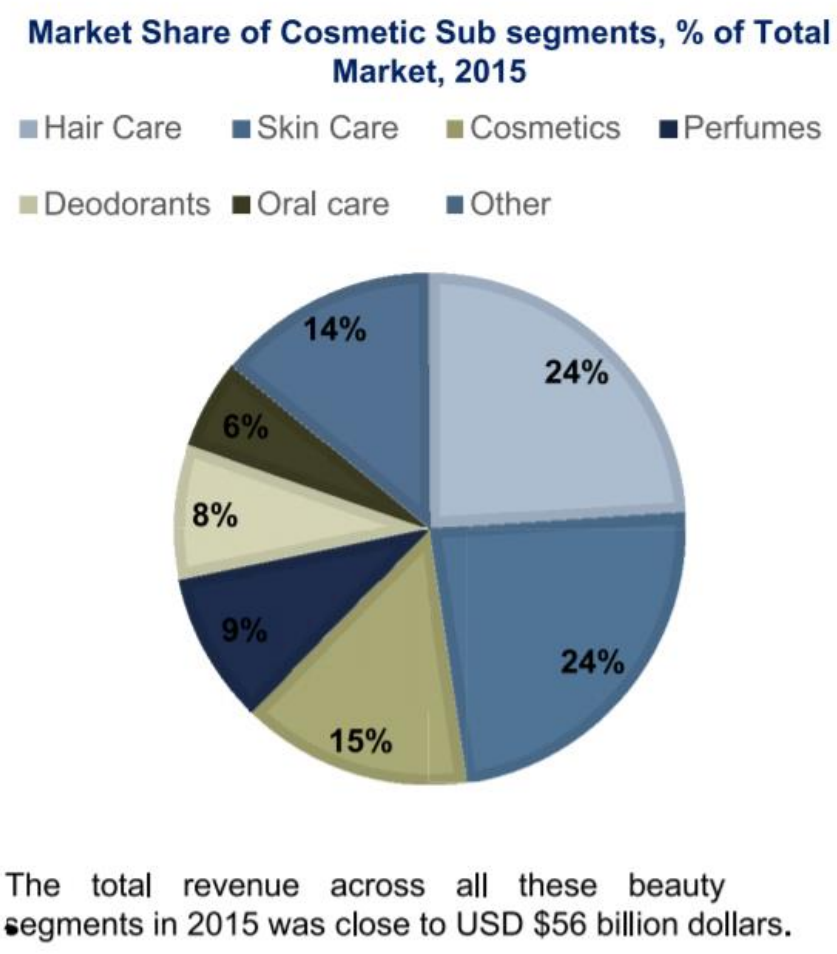

Source: Frost \& Sullivan (2016). Innovations in Cosmetic Procedures (TechVision)

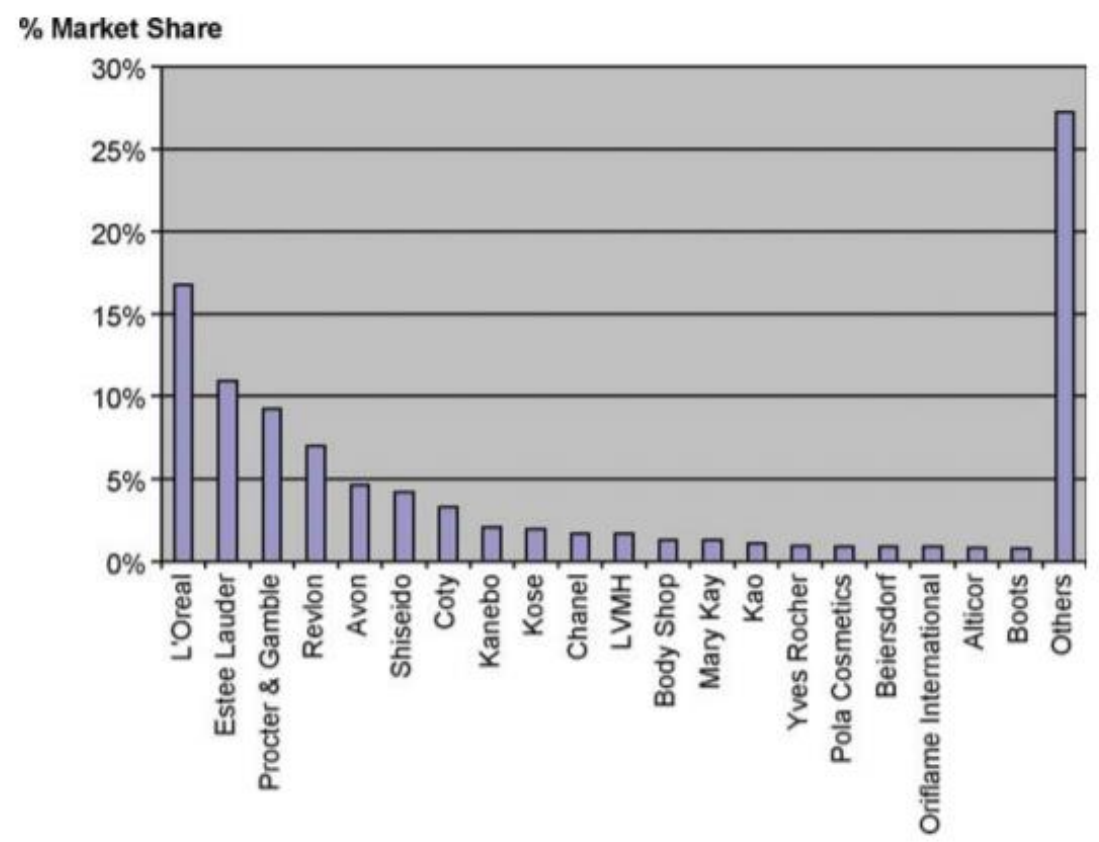

Global color cosmetic sales (market share) in 2000 by leading multi-nationals (Source: Euromonitor (Sauer, 2003)). 


\section{Cosmetic regulations around the globe}

Cosmetic goods are regulated by various regulatory bodies around the globe and all have their own rules and regulations. To understand the view point of the regulatory requirement in different countries we need to understand how these countries are defining the cosmetics as per their legislation.

- India: As per Drugs and Cosmetics Act 1940 and Rules 1945, Cosmetic means any article intended to be rubbed, poured, sprinkled or sprayed on, or introduced into, or otherwise applied to the human body or any part thereof for cleansing, beautifying, promoting attractiveness, or altering the appearance, and includes any article intended for use as a component of cosmetic.

- United States: Defines cosmetics as "articles intended to be rubbed, poured, sprinkled, or sprayed on, introduced into, or otherwise applied to the human body or any part thereof for cleansing, beautifying, promoting attractiveness, or altering the appearance, and articles intended for use as a component of any such articles; except that such term shall not include soap".

- European Union: Defines cosmetics as "any substance or preparation intended to be placed in contact with the various external parts of the human body (epidermis, hair system, nails, lips and external genital organs) or with the teeth and the mucous membranes of the oral cavity with a view exclusively or mainly to cleaning them, perfuming them, changing their appearance and/or correcting body odours and/or protecting them or keeping them in good condition".

We can also harness the definitions of cosmetics as a legal line between cosmetics $\&$ drugs, determine labelling requirements and standards. Although regulations applicable to cosmetic products are increasingly being harmonized to reduce international barriers to trade, there are still important differences to take into account when marketing or selling cosmetics in major markets around the world. 


\section{Before a cosmetic product goes to the market..}

PRODUCT SAFETY AND COMPLIANCE WITH REGULATORY

REQUIREMENTS is paramount and is factored into ingredient selection, final formula selection, and packaging choices to ensure that they are safe for all users

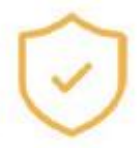

2

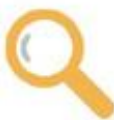

EFFICACY EVALUATION is performed to ensure the cosmetic product delivers on the claims and benefits that are expected by the consumer

3

MICROBIOLOGY conduct test to determine which preservative system is best in order to prevent growth of fungi, bacteria and yeast that could cause cosmetic products to spoil

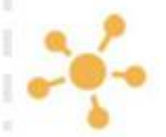

4

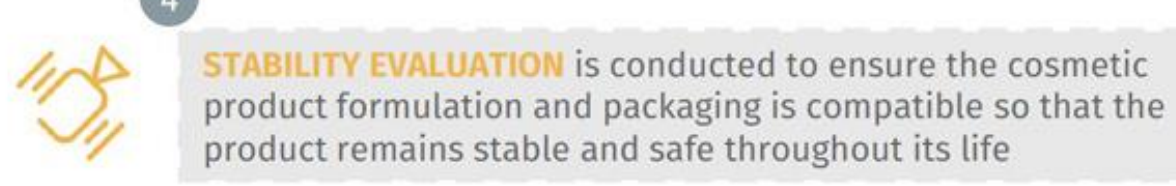

5

PROCESS DEVELOPMENT scales up the cosmetic product

formulation from a small beaker in the lab all the way to huge

vats at the manufacturing site, ensuring quality control is

maintained no matter where it is manufactured in the world

6

SUPPLY CHAIN purchases the materials to make the finished cosmetic product, including raw materials, packaging, and labelling so that the product can be produced in the quantities and quality needed by retailers and customers

\section{Cosmetic Regulation in India}

The cosmetic products in India are regulated under the Drugs and Cosmetics Act 1940 and Rules 1945 and Labelling Declarations by the Bureau of Indian Standards (BIS). BIS sets the standards for cosmetics for the products listed under Schedule ' $S$ ' of the Drugs and cosmetics Rules 1945. BIS has also provided the specification for Skin Creams and Lipstick in the Indian Standards (IS) 6608:2004 and 9875:1990 respectively.

According to IS 6608:2004, all the raw materials requiring test for heavy metals have been so tested and comply with the requirements, then the manufacturer may not test the finished cosmetic for heavy metals and arsenic.

The Rule 134 of Drugs and Cosmetics Rules has laid down restrictions on use of cosmetics containing dyes, colours and pigments other than those specified by the Bureau of Indian Standards (IS: 4707 Part 1 as amended) and Schedule Q. The Rule 145 of the Drugs and 
Cosmetics Rules prohibits use of lead and arsenic compounds in cosmetics for the purpose of colouring. Rule 135 prohibits import of cosmetics in which a lead or arsenic compound has been used for the colouring purpose. Rule $145 \mathrm{D}$ and $135 \mathrm{~A}$ prohibits manufacture and import respectively of cosmetics containing mercury compounds.

\section{Registration of Import of Cosmetics}

A Gazette Notification G.S.R 426(E) dated 19th May 2010 has been issued by the Government of India for amending the Drugs \&amp; Cosmetics Rules, 1945 providing for registration of import of cosmetics into the Country. This provision was to come into effect from the 1st April, 2011. But in view of the various possible difficulties apprehended by the stakeholders, its implementation was deferred till the 31st March, 2013.

All cosmetic products that are imported for sale in India now need to be registered with the Central Drugs Standard Control Organisation (CDSCO) which has been appointed as the licensing authority for the purpose of these rules. This new 'registration' requirement is primarily to regulate indiscriminate import of beauty and personal care products by traders with no accountability for contents and no mechanism to fix responsibility in case a consumer is not satisfied with the quality. The new regulation is an attempt to check the sale of sub-standard cosmetic products and also to harmonise import requirements with products manufactured in India.

\section{What is the Registration Procedure?}

The trade mark owner, who has no manufacturing unit in India but intends to sell his goods by way of import through their appointed importers/distributors/marketers in India, is now required to obtain registration certificate to continue with their marketing activities in India. An application for registration on Form-42, along with all requisite documents needs to be submitted to Drugs Controller General (I), CDSCO, FDA office in New Delhi.

How should one apply?

An application for the issue of a Registration Certificate for cosmetics intended to be imported into India need to be made on a specified form, i.e. Form 42 either by:

1. The manufacturer himself having registered office in India or

2. by his authorised agent or

3. importer in India or

4. by the subsidiary in India authorised by the manufacturer

Further, the documents to be provided along with the application include:

1. A request letter by the applicant on the letterhead of the importer or the authorised agent applying for the registration duly stamped and signed by the authorised person.

2. Form 42 - This requires details such as the location of the actual manufacturing sites of the products. A single application can cover many brands (read Trademarks/brand names), many variants; many pack sizes and different manufacturing units corresponding to the products applied.

3. Proof of payment of requisite fee: Challan indicating the payment of registration fee of USD 2000 or its equivalent in Indian rupees for each 'brand' of cosmetic product and USD 50 for each variant. 
4. Power of Attorney (if the application is being submitted by an authorised agent of the manufacturer. This document needs to be apostilled or legalised by the Indian embassy in that country)

5. Schedule D III (details of the cosmetic products to be imported including the chemical and safety data)

6. Label and art work thereof (this will contain the details of the actual manufacturer and in cases where the manufacturer is not the brand name owner, the label will at least state, 'manufactured in XYZ country')

7. Free Sale Certificate (FSC)/Marketing Authorisation

8. Manufacturing License (and attested English translation if not in English), if any: If there are multiple manufacturers for a single product, all manufacturers need to provide these documents

9. Product specifications and testing protocols: details of ingredients used, quality data etc.

10. List of countries where Market Authorisation or import permission or registration has been granted

11. Package inserts, if any (copies of any leaflets, product specification data that goes inside the packaging has to be provided. No specific requirement has been listed, it is suggested to provide information about the potential side effects/allergic reactions and other safety concerns and remedies available)

12. Copies of the information about the brands, products and manufacturer

\section{What is the timeline for processing of application?}

Within 90 days from the date of submission of the application form and submission of the required documents (especially details required with schedule D III), the registration certificate will be issued.

\section{What is the validity of the registration certificate?}

Registration certificate for import of cosmetics is valid for a period of three years from the date of its issuance. With a view to implementing the provisions of the aforesaid notification and facilitate the registration process for import of cosmetics, there are various guidelines/clarifications and requirements for the grant of Registration Certificate.

\section{Manufacturing of Cosmetics}

The procedure to be followed in order to manufacture cosmetics in India has been laid down under the Drugs and Cosmetics Rules, 1945. A license has to be obtained from a Licensing Authority appointed by the State Government to manufacture any of the cosmetics classified under Schedule M-II. The application has to be submitted in Form 31 along with a license fee and an inspection fee. The manufacturer has to ensure that the production is done in the presence of a competent and qualified technical staff. The Licensing Authority is required to order an inspection of the whole premises where the operations are to be carried out, before granting or refusing the license. The inspectors are appointed under the Act are required to submit a detailed report to the Licensing Authority which can then decide whether to grant the license or not. 


\section{Cosmetic Regulations in Europe}

Since the first directive came into force in the year 1976, the cosmetic regulations in the European union are very strict and all the manufacturers and distributors must comply with them.

\section{Directive 76/768/EEC}

It is the first directive (old directive) published in the year 1976. This legislation continues to be very much present nowadays. It has a virtual influence on the whole world either directly or indirectly. This directive gives a positive definition of cosmetics by including three different characteristics:

1. Cosmetic product: A cosmetic can not only be a mixture, which is what we may traditionally regard it as, but it can also be a single ingredient.

2. Area of application: A list of areas where a cosmetic product can be applied or used is given, in which all areas can be considered as external in so much as mucous membranes can be considered as outwardly.

3. Function: Arguably the most interesting part of the definition as it separates the cosmetic product from any other kind of products based on its intended use.

Together, these characteristics clearly define what constitutes a cosmetic product and allows for the classification into different categories according to one or more of these characteristics. A comprehensive list of this categorization is included in the actual directive so as to better guide the industry towards achieving compliance.

Following the product criteria of the definition, for any cosmetic, be it a single substance or mixture, the ingredients that can be included into its composition have been incorporated into the directive. Due to the vast and ever-growing amount of ingredients being discovered, designed or repurposed, a complete positive list of ingredients is not manageable from a regulatory point of view. Instead, several lists have been included into the annexes of this directive that together aim to control the safety of the cosmetic product for the consumer population.

The lists are as follows:

- Prohibited substances: Including all substances which cannot be part of the composition of a cosmetic product. This list constitutes Annex II of the cosmetics directive.

- Regulated substances: Composed of several lists in which restrictions are set for certain allowed substances in regards to the concentration in the finished product relating also to their function. The lists include:
- Substances included in Annex III
- Colouring agents included in Annex IV
- Preservatives included in Annex VI
- UV filters included in Annex VII

All ingredients which are deliberately introduced into a cosmetic product must appear in INCI (International Nomenclature of Cosmetic Ingredients) nomenclature on the label as per Article 6 of the regulation, in decreasing order of concentration for those over $1 \%$ and in any order for those under $1 \%$. 


\section{Labelling requirements for every cosmetic product the following items must appear on the label:}

- Name and address of the manufacturer or responsible person.

- The nominal content at the time of packaging, in weight of volume.

- The minimum durability date of the product. This can appear as an actual date, as a month/year or, for products with a shelf life of over 30 months, as what is called a PAO (period after opening), which is an indication of the period of time in which the product can be used without harm to the consumer.

- Particular precautions, which may have to do with the presence of a certain ingredient, such as the ones in the regulated lists, a specific presentation or the packaging.

- The batch number of manufactures. This assures traceability of the finished product and is deeply related to the exercise of good manufacturing practices.

- The function of the product, unless it is clear from the presentation.

- The list of ingredients

The Directive itself clearly indicates that each member state must assure the implementation of the standards provided in it, and it does so in Article 3, in which it grants each of these members the supervision over the market control of cosmetics in their country, and full compliance of the industry and final products. Besides, in Article 7a the directive gives the instruction that the competent authority must be notified of the manufacturing of the cosmetic product and that a certain amount of information regarding the cosmetic product must be kept available at the address stated as the responsible person's address.

Being a process left to the disposition of each country, places like Spain adopted a Registration System, by which the product was revised by the authorities and once it was deemed to be compliant with the directive, it would then be authorized for commercial distribution. A part of the information to be kept and to be reviewed by the authorities is a GMP assessment, in which the method of production must be explained and it must follow the good manufacturing practices. Last but not least, a matter of much ethical debate and animal testing. In the old directive, animal testing was not expressly banned, but rather adjusted itself to the good laboratory practices. Animal testing should be limited to practices and tests approved by the health authorities and carried out in the same manner.

New Directive: The new Regulation EC 1223/2009

With it, some crucial and significant changes were made to the cosmetic sector with the aim of making compliance easier and safer for the consumer at the same time.

Following the same order as with the previous directive, the new regulation does not introduce any significant changes to the definition of the cosmetic product. It still includes the triple positive definition of composition, area of application and function. Regarding the composition, another thing that has remained is the classification of cosmetic ingredients into corresponding lists according to whether they are prohibited, regulated based on maximum allowed concentration and function, and allowed substances for specific functions, like colouring agents or UV filters.

However, there are two new additions to the ingredient considerations: CMR substances and Nanomaterials. CMR substances are those that can be carcinogenic, mutagenic or reprotoxic when used, and their inclusion is initially prohibited. Exceptions could however be made if the 
scientific reviews deem it safe for human use in cosmetic form and there are no possible alternatives to their use.

In the case of nanomaterials, the corresponding authorities need to be expressly notified of their presence in the cosmetic product formula and enough data must be available that ensures its safety in human cosmetics. They must also be listed as such in the label so as to inform the consumer of their presence and allow for an informed decision.

No significant changes have been made to the minimum labelling requirements either, the information to be included in it remains the same, but the description and indications given in the Regulation are clearer and more elaborate.

This article clearly states that there must be no kind of implication that the cosmetic product bearing the claims has characteristics or functions that they do not have. This concept is further explored in the Commission Regulation (EU) No 655/2013 of 10 July 2013, dedicated to cosmetic claims in which, among other things, it states that claims are an information tool for the end consumer, and as such, any claim that is included must be proved or substantiated and based on six distinct principles: legal compliance, truthfulness, evidential support, honesty, fairness and informed decision-making. In this way, product assertions are regulated specifically from a health authority standpoint and not only from a publicity and advertisement point.

Rather, responsibilities have been shared out and now each part bears an equal load in regards to product compliance with the Regulation. The figure of the Responsible Person is still present, but the concept has been slightly expanded to include the preparation and custody of what has been deemed a "product information file" or PIF. This PIF is similar to the information dossier that needed to be done under the old Directive 76/768, and it includes a safety assessment report as a main part of it. This PIF must be kept at the premises given for the responsible person and be available upon request of the health authorities for a period of 10 years after the last batch has been placed in the market.

Lastly, the now extinct market authorization (which was basically a registration process) has been substituted by a Notification scheme by which, through electronic means, the responsible person or notifier shall submit a certain degree of information such as the category, name and address of the responsible person, member state in which it was first placed in the market, etc. All this information is enough to identify without a shadow of a doubt the product, the responsible person and the degree of health-relevance that the product might carry.

GMP compliance is a key issue in this regulation. The production method must be described in the PIF, and it should reflect the GMP principles. As seen, inspections can be carried out by the authorities of the member states to assure that the facilities and processes are adapted to the GMP indications. According to the relevant article of the Regulation, Article 8, these GMP shall be drawn from the corresponding harmonized standard, which is to mean, that ISO 22716 is the reference guide to GMP implementation and assessment, and it is this standard by which all manufacturers and distributors must abide by in their activity.

Finally, and as the first regulation to introduce this worldwide, this directive expressly bans all animal testing from cosmetic products and ingredients, and for any testing to be done within the European Union. Instead, valid in vitro methods are to be used for product and ingredient assessment. All new ingredients and products must be sure to ascribe to the valid alternative 
testing methods in order to complete the respective Material Safety Data Sheets and Safety Evaluation Reports.

\section{Cosmetic Regulations in the United States of America}

The Food, Drugs and Cosmetics Act (FD\&C Act) defines two main categories of products:

1. Cosmetics

2. Drugs, including the specific sub-category of over-the-counter (OTC) drugs, which can be sold without prescription.

According to the FD\&C Act, a product may be regarded solely as a drug, solely as a cosmetic or (in contrast to the position in the EU) as both a drug and a cosmetic.

The latter are products that meet the definitions of both cosmetics and drugs. This may happen when a product has two intended uses. For example: An anti-dandruff shampoo is a cosmetic because its claims indicate that the product's intended use is to clean the hair; but It is also considered to be a drug because it contains recognised anti-dandruff ingredients and its claims indicate that it is intended to be used to treat dandruff. Products classified as both cosmetics and drugs must meet the requirements of regulations for both categories of products.

In the USA, cosmetic products are not subject to pre-market approval and companies are not required to submit information on their products or to register cosmetic manufacturing establishments. Manufacturers or distributors of cosmetics may, however, submit information on their products voluntarily through the Food and Drug Administration's (FDA) Voluntary Cosmetic Registration Program (VCRP).

If a cosmetic manufacturer files a product formulation with the VCRP, the FDA can advise the company if it is inadvertently using prohibited or restricted ingredients. Manufacturers can thus correct their formulations before attempting to market them in the USA, thereby avoiding the risk of having their products detained and/or denied entry into the USA because of a prohibited ingredient. Manufacturers may also report any adverse reactions.

Cosmetic labelling is regulated under the FD\&C Act as well as the FPLA (Fair Packaging and Labelling Act). Cosmetic ingredients must be listed by their established name (INCI names) as laid out in the Cosmetics, Toiletries and Fragrances Association (CTFA) International Cosmetic Ingredient Dictionary. The regulations for labelling of cosmetics in United States are controlled by FDA under the authority of the Federal Food, Drug, and Cosmetic Act (FD\&C Act) and the Fair Packaging and Labelling Act (FP\&L Act).

The safety of cosmetic products in the US is the responsibility of the manufacturer, supported by an in-market surveillance system. The FD\&C Act prohibits the distribution of adulterated and misbranded cosmetics and requires that cosmetics must be safe for their intended use before being placed on the market. The Act authorises the FDA to conduct inspections of cosmetic firms (on the basis of complaints or suspicion of violation of law) without prior notice in order to assure compliance with the regulations.

A voluntary process, the Cosmetics Ingredients Review (CIR), was established in 1976. The CIR is funded by the CTFA, with support from the FDA and the Consumer Federation of America. It reviews and assesses the safety of ingredients used in cosmetics and publishes the results in the scientific literature. Ingredients are selected for review on the basis of their 
potential biological activity, frequency of use in cosmetics and extent of skin penetration, amongst other factors.

FDA strongly urges cosmetic manufacturers to conduct whatever toxicological or other tests are appropriate to substantiate the safety of their cosmetics. However, they are not mandatory.

In the current amendment, on 2010 July 7 Human Resources (HR) 5786 Chapter VI of the Food, Drug and Cosmetic Act, which concerns adulterated and misbranded cosmetics, by adding a subchapter on the regulation of cosmetics.

Act to expand the regulation of cosmetics, including requiring:

- Annual registration of any establishment engaged in manufacturing, packaging, or distributing cosmetics for use in the United States;

- New fees to provide for oversight and enforcement of cosmetics regulations;

- Ingredient labelling and disclosure of information on ingredients; and

- Adverse event reporting

\begin{tabular}{|c|c|c|c|}
\hline CONIENTS & USA & EU & INDIA \\
\hline $\begin{array}{l}\text { AUTHORITY } \\
\text { RULES AND } \\
\text { REGULATIONS }\end{array}$ & $\begin{array}{c}F D A \\
F O O D, D R U G A N D \\
C O S M E \Pi C A C I\end{array}$ & $\begin{array}{c}\text { EMEA } \\
\text { COUNCIL } \\
\text { DIRECTIVE } 76 / 768 / E E C\end{array}$ & $\begin{array}{c}\text { CDSCO } \\
\text { DR UGS AND } \\
\text { COSMETICS ACt }\end{array}$ \\
\hline $\begin{array}{l}\text { PRE-MARKET } \\
\text { APPROVAL }\end{array}$ & Not required & $\begin{array}{c}\text { Not required by } \\
\text { Cosmetic Directive }\end{array}$ & $\begin{array}{l}\text { Require dunder state } \\
\text { government licensing }\end{array}$ \\
\hline LABELLING & $\begin{array}{l}\text { hould comphy with the } \\
F D \& C \text { and } F P \& L\end{array}$ & $\begin{array}{c}\text { Based on Council } \\
\text { Directive } 76 / 768 / E E C\end{array}$ & $\begin{array}{l}\text { Should comply } \\
\text { with part } \\
X V \text { of } D \& C \\
\text { rules } 1945\end{array}$ \\
\hline EXPIRY DATE & No date required & $\begin{array}{l}\text { Date of minimum } \\
\text { durability if durability } \\
\text { is <30 months. Period } \\
\text { affer opening if } \\
\text { durability is } \\
>30 \text { months }\end{array}$ & $\begin{array}{l}\text { Indicated as } \\
\text { "Use before date" }\end{array}$ \\
\hline $\begin{array}{c}\text { POST } \\
\text { MARKEIING } \\
\text { REPORTING } \\
\text { SYS IEM }\end{array}$ & $\begin{array}{c}\text { Yes. Voluntary } \\
\text { Cosmetic Registration } \\
\text { Program }\end{array}$ & $N / A$ & $N / A$ \\
\hline
\end{tabular}

A comparison of cosmetic regulations between USA, EU and India.

(Srikanth.T, et al, 2011)

\section{The Regulation of Personalized Cosmetics in the EU}

Personalized or customized cosmetics are increasing in popularity. While compliance with the EU Cosmetics Regulation 1223/2009 is mandatory, there are no clear guidelines to ensure their compliance. While cosmetic products are subject to numerous regulations, permitting their sale within the European Single Market, this article focusses on the requirements of the Cosmetics Regulation 1223/2009.

It is a widely established trend that consumers like to personalize their cosmetic products. They want to choose the ingredients in the product according to their skin or hair characteristics with the idea of having unique products that are more effective than off-the-shelf products. 
While the Regulation does not explicitly mention or address personalized products, if the definition of cosmetic is met (a product intended to be placed in contact with the external parts of the human body with the intention of cleaning them, perfuming them, changing their appearance, protecting them, keeping them in good condition or correcting body odours), then the product must comply with the Regulation. This poses several challenges to retailers and/or manufacturers. These include ensuring good manufacturing practice (including the identification of manufacturing site or sites) and assessing the safety of a product that has a variable composition.

As the Regulation 1223/2009 states, "for each cosmetic product placed on the market, the responsible person shall ensure compliance with the relevant obligations" set out in the Regulation.

Personalised cosmetic manufacturing, difficulty in their compliance and possible solution

1. Classical manufacturing facilities: The customer completes an online questionnaire choosing their preferred properties; the product is then manufactured and shipped to the home.

2. Retail stores that offer the possibility of blending the product on-site at the point of purchase.

3. Domestic blending devices

4. Personalization by adding active ingredients or boosters to regularly used cosmetic products (e.g., a few drops of Vitamin $\mathrm{C}$ added to a regular moisturising cream).

\section{Compliance}

1. Article 8 of the Cosmetics Regulation: Good Manufacturing Practice Cosmetic manufacturing facilities must work according to good manufacturing practice (GMP). This ought not to present a challenge to products formulated or manufactured in regular manufacturing facilities (i.e., personalized products that are purchased online).

However, the challenge is significant when preparing the cosmetic product in situ (i.e., at the retailer's store). If a device is used, the device becomes the "manufacturing facility" and should thus comply with good manufacturing practices. This means the device should be regularly calibrated and standardized in order to ensure that volumes dispensed are accurate and consistent. Devices should also be kept in a good hygienic condition and people using the device should be adequately trained to ensure proper use and maintenance. If no device is being used, but a person is preparing the product at the store, efforts should be directed towards ensuring that person is properly trained, dispensing materials are calibrated and the environment is clean. If the device is used at home, a high level of automation is expected, but GMP compliance is still expected (again, the device becomes the manufacturing facility). The device should be designed to ensure accuracy and hygiene when manipulated by the consumer at home. Additionally, clear and accurate directions for use should be provided to the consumer to ensure the manufacturing process results in a safe cosmetic product.

2. Article 10 of the Cosmetics Regulation: Safety Assessment

A safety assessment must be performed prior to placing a cosmetic product on the market, that is, before the customer takes the product home or the product is received at home. If the customized cosmetic product is ordered online and shipped home, the 
timeframe is manageable, as the product's composition is well known before the final product reaches the consumer and the safety assessment can be prepared in advance.

A bigger challenge exists if the exact product composition is not known in advance, i.e., if the product is designed and blended at the retail store. In this case, Responsible Persons should be able to foresee all possible combinations of ingredients their cosmetic products can have and prepare a safety assessment for each combination, so than any possible product they place on the market is covered. Nevertheless, a safety issue may arise with this type of product (blended at the retailer's store): Microbiological quality of the product will most probably not be checked, due to practical reasons, and it is therefore questionable if a safety assessor will consider a product is safe if these data are lacking.

When a device is used at home, the final product composition after mixing the contents of the several cartridges will be known. As already mentioned above, this can be considered a cosmetic kit and therefore a safety assessment can be performed before the product reaches the consumer.

3. Article 12 of the Cosmetics Regulation: Sampling and Analysis

Assuming sampling and analysis of the cosmetic product after manufacturing is performed "in a reliable and reproducible manner" as required by the Regulation, the challenge is space and capacity limitations if a sample of each manufactured batch must be kept. In regular manufacturing facilities, numerous small batches will be produced instead of one single big batch: each manufacture for every single customer will be a different batch. The same applies to actives or boosters. In these two cases, no sampling will be performed for the finished product (the one resulting from the mixture of the different components): As the product is used immediately after mixing, there is no product left for storage that could have any stability issues.

4. Article 13 of the Cosmetics Regulation: CPNP Notification

As for the safety assessment, a notification, via the Cosmetic Product Notification Portal (CPNP), must be submitted prior to placing the cosmetic product on the market. For products blended at home, if we consider them as a kit, then notification is achievable in advance. For actives or boosters, they can be notified as single components; notification of the finished product (after mixing with the base) will only be possible if products from the same brand are used or if brands co-operate and disclose ingredients. As for the PIF (Product Information File), if labels are the same for equal compositions, only a single notification will be needed for a given product.

5. Article 19 of the Cosmetics Regulation: Labelling

According to the Regulation, cosmetic products must include the following items in the product label: Responsible Person details, country of origin (if outside the EU), nominal content, date of minimum durability or Period After Opening (PAO), precautions and directions for use, batch number, function of the product and list of ingredients.

6. Article 23 of the Cosmetics Regulation: Communication of Serious Undesirable Effects. As defined in the Regulation, a serious undesirable effect is an adverse reaction for human health attributable to the normal or reasonably foreseeable use of a cosmetic product resulting in temporary or permanent functional incapacity, disability, hospitalization, congenital anomalies or an immediate vital risk or death.

7. Article 3: A cosmetic product shall be safe for human health taking into account presentation, labelling and instructions for use. 
8. Articles 14 to 17: No banned ingredients or ingredients above restricted levels shall be used when formulating a cosmetic product.

9. Article 18: Products must comply with the animal testing ban.

10. Article 20: Claims used in cosmetic product shall be supported by the appropriate evidence and shall be compliant with Regulation 655/2013 on cosmetic claims.

11. Articles 21 and 24: Information on the product's composition and existing data on (serious) undesirable effects shall be made publicly accessible.

\section{Research and Innovation as a constant driving force for the cosmetic industry}

The global cosmetic industry is constantly developing. It is characterised by regular growth and high competitiveness. At the same time for numerous companies' innovation seems to be the vehicle of growth.

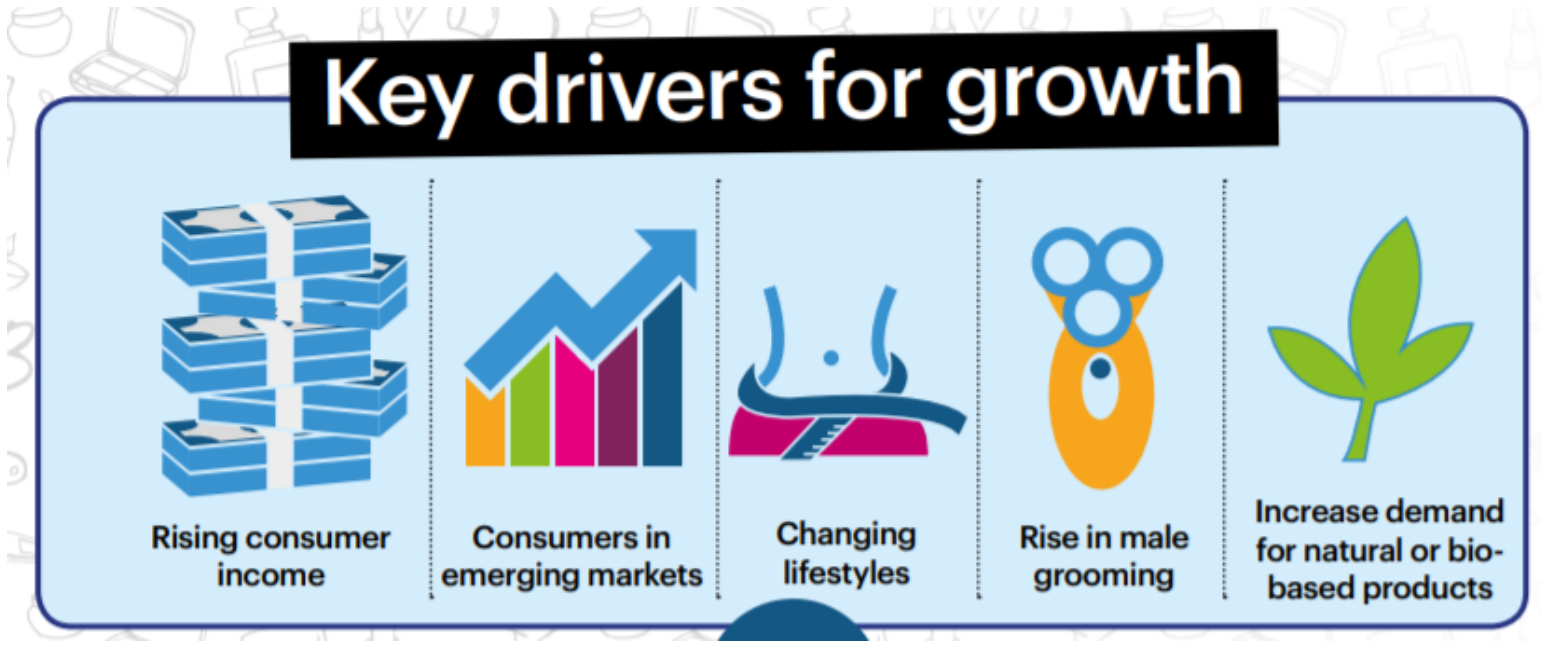

The beauty market is generally categorized into five segments as follows: (1) skincare (2) hair care (3) colour cosmetics (4) fragrances and (5) toiletries. Also, cosmetic products can be divided into premium segment and the mass market. The premium segment represents $28 \%$ of total sales worldwide and the second one accounts for $72 \%$.

The cosmetic industry is dominated by multinational companies. Five main cosmetic companies worldwide are

1. L'Oréal with sales of 30.52 billion dollars

2. Unilever with sales of 21.33 billion dollars

3. Procter\&Gamble with sales of 20.5 billion dollars

4. Estee Lauder with sales of 10.39 billion dollars

5. Shiseido with sales of 7.77 billion dollars

Product innovation is essential in gaining competitive advantage in the cosmetic industry. Because of the short life cycle of beauty products cosmetic companies are constantly introducing new product innovations or improving current products.

Product innovation is diversified depending on the level of

- novelty: world novelty,

- incremental product improvement, 
- new line of products,

- product repositioning,

- product line expansion and

- cost reduction.

Moreover, the beauty industry is "characterized by the constant necessity to release new products and high dependence on new ingredients, especially essences and functional actives". Also, brands are crucial in building competitive advantage among competitors. Cosmetic fi rms increase potential of existing brands and offer new ones.

Cosmetic industry reinvents every day making that trends in skincare, make-up or hair care from a decade ago are now obsolete. The most successful products in the market are the ones that have studied their environment and perform the latest innovations in ingredient design, product development, packaging or storytelling.

We can summarize the latest trends related to innovations and research as follows:

1. Simplify skin care routine: less products with better ingredients

With the expansion of Korean cosmetic brands to western countries, countless consumers adopted the 10-steps of Korean skin care routine. The basis of this routine says that cleaning and feeding your skin will make it bloom. To follow this routine there are several products that are needed, basically: an oil cleanser, a foam or cream cleanser, a toner, an essence, an emulsion, a serum, a sheet mask, eye cream, moisturizer, and, finally, sunscreen.

\section{Bioengineered ingredients: natural and sustainable}

Cosmetic preferences have switched over the past decade from classic to green products with natural ingredients. However, consumers are now more aware that natural does not always mean clean or nature-friendly. For example, some natural ingredients coming from extensive crops decrease biodiversity and promotes deforestation. As a result, consumers are now shifting towards products with "green" labels but also with proven efficacy. These products contain bioengineered actives that optimise natural ingredients. Bioengineered ingredients are molecules coming from plants, microorganisms, algae, where the desired molecule is extracted and optimise using biotechnological techniques such as bio-fermentation. The use of biotechnology allows cosmetic industry to achieve sustainable ingredients redefining the concept of natural cosmetics.

\section{Zero Waste and waterless beauty}

Cosmetic industry, as any other industry, needs to improve and do better in order to achieve zero waste goal by making recyclable every component of a cosmetic product. It is known that plastic has become a major issue in natural landscapes, we need to reduce plastic waste and its accumulation in oceans. To contribute in this, cosmetic industry must use more sustainable packaging, by changing classic disposable plastics to more biodegradable and green components. But, in order to achieve the zero-waste goal, it is necessary to use recyclable elements also in formulation by using biodegradable ingredients, and reducing the quantity of water in final product 
formulations. This reduction in formulation water is called waterless beauty, and is expected to be a trend itself in 2020 .

4. Living cells are being researched as ingredients to increase the bioactive effect, including stem cells and algae. Stem-cell based technologies have had a major impact across the medical community and the presence of these stem-cell skin cosmetic products is also rather substantial. When considering stem cell technologies in this, not always regulated, industry the rules governing the internal clinical trials carried out gain importance.

5. Design of nano-ingredients. Nanoparticles and liposomes acting as vehicles for delivery of bioactive ingredients.

6. Development of bioactive mixtures and extraction technologies for hair care, antiageing, UV-free tanning, baby care, slimming, and several other segments of the personal care industry.

7. Virtual reality and IoT: Technologies based on virtual reality and Internet of Things (IoT) are expected to have more and more impact on the cosmetic industry due to the proliferation of digital media among consumers. On-line advertising and marketing are in addition to the contents of social networks, mobile personalisation applications, various examples of interconnected skin care devices, reality virtual, augmented reality and IoT. These highly complex and sophisticated technologies have a major impact across various verticals and their adoption is the best way to improve marketing strategies to boost consumer experience.

\section{References and further read:}

1. Abdullah B J, Nasreen R, Ravichandran N. A COMPARATIVE STUDY OF COSMETIC REGULATIONS IN DIFFERENT COUNTRIES OF THE WORLD WITH FOCUS ON INDIA International Journal of Current Research and Review. Vol 04 Issue 11, June, 131-144

2. BCC Research GLOBAL MARKETS FOR CHEMICALS FOR COSMETICS AND TOILETRIES

3. Eixarch, H., Wyness, L., \& Sibanda, M. (2019). The Regulation of Personalized Cosmetics in the EU. Cosmetics, 6(2), 29.

4. EY's Luxury \& cosmetics financial factbook 2013

5. Global Beauty Care Products Industry 2012-2017: Trend, Profit, and Forecast Analysis - September 2012

6. Global Cosmetics Manufacturing Market Research report - IBISWorld

7. Global Industry Analysis, Size, Share, Growth Trends and Forecast, $2012-2018$

8. Global Industry Analysts - Cosmetic Chemicals: A Global Strategic Business Report Nov 2013

9. Global Industry Analysts - Cosmetic Chemicals: A Global Strategic Business Report Nov 2013

10. https://cosmeticsinfo.org/Regulation-in-eu 
Mohd Riyaz Beg, M. Pharm (Pharmacology), Institute of Chemical Technology, Mumbai

11. Kumar, S. (2005). Exploratory analysis of global cosmetic industry: major players, technology and market trends. Technovation, 25(11), 1263-1272.

12. Kumar, S., Massie, C., \& Dumonceaux, M. D. (2006). Comparative innovative business strategies of major players in cosmetic industry. Industrial Management \& Data Systems.

13. Product innovation in Cosmetics, hubb30.

14. Raj, R. K., \& Chandrul, K. K. (2016). Regulatory Requirements for Cosmetics in Relation with Regulatory Authorities in India against US, Europe, Australia and Asean Countries. Int J Pharma Res Health Sci, 4(5), 1332-1341.

15. Singh, B. M., Jain, A., \& Mishra, A. (2018). Cosmetic Regulations in India vs. Globally and Challenges in Harmonization. International Journal of Pharmaceutical Sciences and Drug Research, 10(3), 150-157.

16. South Korea: Thinking global, Cosmetics Business 2013 and RNCOS.

17. Szutowski, D., \& Szułczyńska, J. (2016). PRODUCT INNOVATION IN COSMETIC INDUSTRY-CASE STUDY OF MAJOR COSMETIC COMPANIES. In SOCIAL RELATIONS AND CONFLICTS IN CONDITIONS OF INTENSIFICATION OF ECONOMIC PROCESSES AND DOMINANCE OF LIBERAL IDEOLOGY (pp. 2021).

18. Transparency Market Research's Organic Personal Care Products Market for Skin Care, Hair Care, Oral Care and Cosmetics 